\title{
Desire for control and personality as predictors of three communication traits in a public speaking context
}

\author{
Peter Daniel MacIntyre $\mathbb{I D}^{A, C, D, E, F, G}$, Emily MacKay ${ }^{A, B, C, D, E, F}$ \\ Cape Breton University, Sydney, Canada
}

\section{BACKGROUND}

Communication in general, and public speaking in particular, are important means to exert influence over other people; control is an enduring motive for communication. People differ substantially in the amount of control they typically want; some seek control and others tend to avoid it. But is the desire for control (DC) redundant with more basic personality traits in predicting individual differences related to public speaking?

\section{PARTICIPANTS AND PROCEDURE}

This study, conducted with 196 undergraduate students using well-established measures, examines correlations among desire for control, the Big Five, and three communication traits specifically referencing public speaking: willingness to communicate, perceived competence, and public speaking anxiety. The measures were administered by questionnaire.

\section{RESULTS}

Correlations show that people with higher DC tend to be more willing to communicate and perceive themselves to be more competent and, to a weaker extent, less anxious. Hierarchical multiple regressions show that the role of DC is not redundant with Big Five personality traits in predicting willingness to communicate and self-perceived competence, but also that DC does not significantly add to predicting public speaking anxiety.

\section{CONCLUSIONS}

Speaking in a public context may be especially attractive to persons with a desire for control who tend to feel both willing and able to communicate. Public speaking anxiety appears less consistently related to individual differences in DC.

\section{KEY WORDS}

willingness to communicate; Big Five; communication apprehension; perceived competence; hierarchical multiple regression

Corresponding AUthor - Peter Daniel Maclntyre, Ph.D., Cape Breton University, 1250 Grand Lake Road, B1P6L2 Sydney, Canada, e-mail: peter_macintyre@cbu.ca

AUthors' CONTRIBUtion - A: Study design - B: Data collection · C: Statistical analysis - D: Data interpretation .

E: Manuscript preparation · F: Literature search · G: Funds collection

TO CITE THIS ARTICLE - MacIntyre, P. D., \& MacKay, E. (2019). Desire for control and personality as predictors of three

communication traits in a public speaking context. Current Issues in Personality Psychology, 7(3), 212-219.

RECEIVED 16.03.2018 · REVIEWED 05.07.2019 • ACCEPTED 06.07.2019 · PUBLISHED 30.09.2019 


\section{BACKGROUND}

Communication is an important means to exert influence over other people; and control is one of the key, enduring motives for interpersonal communication (Bochner, Kaminski, \& Fitzpatrick, 1977; Burgoon \& Hale, 1984; Millar \& Rogers, 1976; Rubin, Perse, \& Barbato, 1988). It has been recognized for quite some time that people differ substantially in the amount of control they typically desire; in short, some seek control and others tend to avoid it (Burger, 1992; Huang, 1999). Experimental and correlational research has identified relationships between desire for control and self-esteem (Gebhardt \& Brosschot, 2002; Huang, 1999), age (Smith, Wallston, Wallston, Forsberg, \& King, 1984; Woodward \& Wallston, 1987), gender (Burger, 1992; Burger \& Solano, 1994), education level (Burger, 1992; Smith et al., 1984; Smith et al., 1988), and within family communication styles (Huang, 1999). However, only two studies to date have focused directly on the relationship between desire for control and communication traits (MacIntyre \& Donovan, 2004; Wrench, Brogan, McCroskey, \& Jowi, 2008).

Prior research has connected broadly defined communication traits, such as communication apprehension, willingness to communicate and perceived competence, with a host of other widely applicable, broadly defined personality traits such as extraversion and neuroticism (MacIntyre, Babin, \& Clément, 1999; McCroskey, Heisel, \& Richmond, 2001; Richmond \& McCroskey, 1985; Yu, Li, \& Gou, 2011). However, the communication-trait correlates of more circumscribed and situation-specific dimensions of personality, such as desire for control, and more specific communication traits, such as public speaking anxiety, have not been widely reported. Identifying narrowly defined traits that are relevant in specific communication contexts lends itself to identifying particular processes that are involved in connecting personality to communication. This study will examine the correlations between desire for control and three communication traits associated with public speaking - anxiety, perceived competence, and willingness to communicate. Public speaking is a context in which a speaker often tries to influence the actions of others and therefore provides a delimited, appropriate setting in which to investigate individual differences in the desire for control.

\section{DESIRE FOR CONTROL (DC)}

As defined by Burger (1992), desire for control (DC) is "the extent to which people generally are motivated to see themselves in control of the events in their lives" (p. 6). As with other dispositions, DC can be placed on a continuum. Those with high DC are described as assertive, decisive, and more likely to take on a leadership role; those with low DC tend to show the opposite tendencies (Burger, 1992). However, as Burger (1992) suggested, it is possible to have high levels of DC regardless of other traits or characteristics. For example, it might be assumed that ideal leaders are charismatic, confident, outgoing; they seek to control their environment and are often good communicators (Kuofie, Stephens-Craig, \& Dool, 2015; Missioura, 2014; Zaccardi, Howard, \& Schnusenberg, 2012). Extraverts possess many of the traits assumed good for leadership. However, studies have shown that successful introverted leaders tend to be thoughtful and consider information in more detail before making decisions or communicating about issues (Kello, 2012), indicating that introverts also can be effective in leadership roles (Kuofie et al., 2015). The DC that accompanies leadership aspirations has shown a small, non-significant correlation with extraversion (Burger, 1992), indicating that as a group neither introverts nor extraverts necessarily seek out higher levels of control.

Burger (1992) hypothesized that persons with greater DC tend to dominate social interactions by controlling the conversation and communicating more often than persons with a low DC. He described two possible ways in which a person's DC can affect their communication patterns:

"People high in desire for control may take very active steps to control the flow of the interaction. For example, they might introduce or change the topic of the conversation to satisfy their own needs and hidden agendas. High desire for control people probably become proficient at developing and utilizing personal influence strategies that allow them to get what they want out of their interactions with others. However, a second possible strategy for control might be to play a more reserved role in the interaction. That is, conversations can also be a threat to one's sense of personal control. Revealing information about oneself might be seen as a risky action, whereas finding out about this other person first (e.g. where does he or she stand on this issue? Can I trust this person with intimate information about me?) might put the high desire for control person in a more powerful and controlling position" (Burger, 1990, p. 34).

Supporting Burger's (1992) participation and proficiency hypothesis, two studies (MacIntyre \& Donovan, 2004; Wrench et al., 2008) both identified a positive relationship between DC and willingness to communicate (WTC), but diverged in other relevant results. In particular, the correlation between DC and communication apprehension (CA) which was significant for Wrench et al. (2008) was not for MacIntyre and Donovan (2004). Burger (1992) also discussed a possible relationship between anxiety and DC, hypothesizing that those with lower DC tend to have lower trait anxiety. However, Iba (2007) suggested that persons with higher perceived control might 
have higher anxiety because they fear losing control of communication with an unpredictable audience in public speaking. The inconsistencies across studies suggest that there is a complex process taking place that might implicate other personality traits in communication behavior.

\section{BROAD PERSONALITY TRAITS - THE BIG FIVE}

The literature on personality psychology has no shortage of traits available for study; Allport and Odbert (1936) list 17,958 trait-related words in the English language. Obviously, there are redundancies in a list that size, and personality traits have grouped in a variety of taxonomies (Funder, 2010). Over the years competing ideas on the structure of personality and how to measure it have arisen in large part because different definitions and classifications of traits often overlap, creating conceptual redundancies. However, in the early 1990s, a consensus emerged around five core dimensions of personality that can be shown to be both independent (relatively uncorrelated) and applicable across a wide range of situations. Goldberg (1992) labeled these traits "The Big Five": extraversion-introversion (i.e. talkativeness and assertiveness versus silence and passivity), agreeableness-antagonism (i.e. kindness and trust versus hostility and selfishness), conscientiousnesslack of direction (i.e. organization and thoroughness versus carelessness and negligence), neuroticismemotional stability (i.e. nervousness and feelings of inadequacy versus calmness and self-assurance), and intellect or openness to experience (i.e. imagination and curiosity versus shallowness and imperceptiveness) (see also Costa \& McCrae, 1985; John \& Srivastava, 1999; McCrae \& John, 1992).

The Big Five traits predict communication patterns, with introversion-extraversion perhaps being the most obviously applicable trait. Compared to extraverts, introverts tend to report more communication apprehension (CA) and perceive themselves as less immediately responsive (McCroskey et al., 2001). Introverts also report being less willing to communicate (WTC) and lower in levels of self-perceived communication competence (SPCC; MacIntyre et al., 1999; Richmond \& McCroskey, 1985). Compared with introversion, the neuroticism-emotional stability trait dimension shows a similar consistent pattern of correlation with communication traits of WTC, SPCC, and CA. Yu, Li, and Gou (2011) suggested that persons with high emotional stability tend to experience greater self-esteem and WTC, but those with low emotional stability tend to have higher CA. Over the years, the other Big Five traits have generated fewer studies and few significant correlations with communication traits. Although most research has indicated that personality tends to have a stronger influence on trait-like communication apprehension (McCroskey, 1982; Sloan \& Slane, 1990), it has long been argued that more narrowly defined constructs, such as public speaking anxiety (PSA), can allow for a clearer focus on specific communication processes (Hensley \& Batty, 1974; McCroskey, 1970).

\section{AND COMMUNICATION TRAITS IN PUBLIC SPEAKING CONTEXTS}

In the present study, we will focus on three communication traits with theoretical relevance to public speaking, that also have established scales to measure public speaking contexts: Public Speaking Anxiety (PSA), Willingness to Communicate within Public Speaking contexts (WTC-PS), and Self-Perceived Communication Competence in Public Speaking contexts (SPCC-PS) (see McCroskey \& Richmond, 1991). If public speaking offers a means of exerting control over the thoughts and actions of other persons, then we would expect a positive correlation between WTC-PS and the desire for control (DC). In general, WTC is defined by the readiness to initiate discourse (McCroskey \& Richmond, 1991), and it is clear that some people approach and others avoid public speaking. Furthermore, in terms of communicating in a public setting, being willing and able are not the same. So if WTC-PS reflects being willing to engage in public communication, theoretically we expect that two preconditions also are being met (see MacIntyre, 1994; McCroskey \& Richmond, 1991). Specifically, speakers who possess more willingness to speak are also likely to possess greater competence to achieve their communicative goals and lower anxiety. If DC is a factor leading to engagement with public communication, then we also expect DC to positively correlate with SPCC-PS given that control is at least partially rooted in competence (Amoura, Berjot, Gillet, \& Altinas, 2014). Finally, even if a speaker feels competent, the arousal of anxiety or communication apprehension can generate inhibition, hesitation, and a desire to hold back from talking (McCroskey, 1982). Although CA has been widely studied and has been consistently related to both WTC and SPCC (McCroskey et al., 2001), we noted above that there have been conflicting findings concerning the relationship between anxiety and DC. Therefore, it is an open question whether DC will correlate significantly with PSA or not. It also is an open question whether DC makes a significant contribution to predicting communication traits beyond the prediction offered by the Big Five. In brief, if we have scores on the Big Five, does DC offer any additional predictive value?

The present study addresses the above research issues by examining two research questions:

RQ1: What are the patterns of correlation between DC, the Big Five traits, PSA, WTC-PS, and SPCC-PS? 
Given the potential for overlap among personality traits and DC, additional analysis will use hierarchical multiple regression to examine whether the addition of DC explained additional variance in the communication traits over and above the variance explained by the Big Five.

RQ2: Does DC add to the prediction of public speaking communication traits over and above the Big Five traits?

\section{PARTICIPANTS AND PROCEDURE}

\section{PARTICIPANTS}

Participants $(N=196 ; 70 \%$ female; aged $18-40,92 \%$ aged 18-25) were all undergraduates from Cape Breton University enrolled in Bachelor of Arts (40\%), Science (51\%), Nursing (6\%) and Business (3\%). Almost half of the participants were in their first year (48\%), with second year (26\%), third year (18\%) and fourth year (7\%) students also volunteering to complete the study. Participants were recruited from various programs with the permission of course professors and offered extra credit if it had been made available by their professor as part of a course syllabus. Participants were given 30 minutes to complete the questionnaire containing the following measures. Note that all means reported reflect the scale total divided by the number of items.

\section{MEASURES}

Personal Report of Public Speaking Anxiety Scale. To assess each participant's level of public speaking anxiety, the 34-item Personal Report of Public Speaking Anxiety (PRPSA) scale was used (McCroskey, 1970) with a seven-point Likert response scale. Cronbach's $\alpha$ indicated very good reliability $(\alpha=.97$, $M=3.51, S D=0.62)$.

Willingness to Communicate Scale. The McCroskey and Richmond (1987) 20-item Willingness to Communicate (WTC) scale was administered with responses given on the same seven-point Likert scale as with the PSA measure. Only the three-item public speaking subscale is used in the analyses below. An acceptable reliability coefficient was obtained $(\alpha=.80, M=1.48, S D=0.51)$.

Self-Perceived Communication Competence Scale. The 12-tem Self Perceived Communication Competence (SPCC) scale (McCroskey \& McCroskey, 2013) was administered with a seven-point Likert response scale. Similar to WTC, only the three items referring to the public speaking context (SPCC-PS) were used in the analysis. The reliability coefficient was acceptable $(\alpha=.78, M=1.51, S D=0.48)$.

Big Five Personality Inventory Scale. A 44-item Big Five Inventory (BFI; John \& Srivastava, 1999) was ad- ministered with a seven-point Likert response scale. The obtained Cronbach's $\alpha$, mean and standard deviations are as follows: introversion $(\alpha=.86, M=3.70$, $S D=1.14)$, agreeableness $(\alpha=.75, M=5.28, S D=0.79)$, conscientiousness $(\alpha=.71, M=4.63, S D=0.78)$, neuroticism $(\alpha=.81, M=4.24, S D=1.12)$, and openness $(\alpha=.76, M=4.58, S D=0.87)$.

Desirability of Control Scale. To measure desire for control, Burger and Cooper's (1979) Desirability of Control Scale (DOCS) was used, with a seven-point Likert-response format. Cronbach's $\alpha$ was acceptable $(\alpha=.74, M=4.71, S D=0.62)$.

\section{RESULTS}

To examine RQ1, correlations were computed among DC, the Big Five traits, and the three communication traits. In the first column, Table 1 shows a significant correlation of DC with WTC-PS $(r=.41)$ and SPCC-PS $(r=.40)$, and a smaller, significant negative correlation with PSA $(r=-.16)$. The pattern of correlations shows that respondents with higher levels of DC tend to be more willing to communicate, perceive greater communicative competence, and tend to report somewhat lower levels of anxiety when communicating in public situations.

The next set of correlations examines the relationship between the Big Five personality traits and the three communication traits. The results suggest that introversion and neuroticism show similar correlation patterns; both traits are correlated positively with PSA (I, $r=.35 ; \mathrm{N}, r=.51$ ), negatively with WTC-PS (I, $r=-.61$; N, $r=-.36$ ), and negatively with SPCC-PS (I, $r=-.53$; N, $r=-.44$ ). Conscientiousness is the only other trait that shows significant correlations with any of the communication traits, obtaining a small positive correlation with both WTC-PS $(r=.20)$ and SPCC-PS $(r=.18)$.

Given the research question, we also focus on possible relationships between DC and the Big Five traits. The results indicate a significant negative correlation between DC and both introversion $(r=-.30)$ and neuroticism DC $(r=-.22)$, but a significant positive correlation between DC and conscientiousness $(r=.23)$. Neither Agreeableness nor Openness shows a significant correlation with DC (see Table 1).

To examine RQ2, a hierarchical multiple regression (HMR) analysis was conducted. Given that we were concerned with the Big Five as a set of traits, we chose the enter method to generate the regression equation, with each of the regression coefficients tested for significance. We entered the Big Five traits as a block into the equation in step 1, followed by DC in step 2 . Using WTC-PS as the criterion, the results show that three of the Big Five traits contributed significantly to the regression in Model 1: introversion, conscientiousness, and neuroticism $(R=.64, F(5,189)=26.31$, 
$p<.001)$. Model 1 accounts for approximately $41 \%$ of $\quad$ predicators $(R=.65, F(6,188)=25.11, p<.001)$, with the variance. When DC was added to create Model 2, Model 2 adding 3.5\% of explained variance in WTC-PS only introversion and DC remained as significant (see Table 2 for the regression equation).

Table 1

Correlations among the Big Five traits, desire for control and the three communication traits

\begin{tabular}{|c|c|c|c|c|c|c|c|c|c|}
\hline & DC & I & A & $\mathrm{C}$ & $\mathrm{N}$ & $\mathrm{O}$ & WTC-PS & SPCC-P & PSA \\
\hline Desire for control (DC) & 1 & - & - & - & - & - & - & - & - \\
\hline Introversion (I) & $-.30^{* *}$ & 1 & - & - & - & - & - & - & - \\
\hline Agreeableness $(\mathrm{A})$ & -.05 & -.07 & 1 & - & - & - & - & - & - \\
\hline Conscientiousness (C) & $.23^{* *}$ & -.11 & $.41^{* *}$ & 1 & - & - & - & - & - \\
\hline Neuroticism $(\mathrm{N})$ & $-.22^{* *}$ & $.41^{* *}$ & -.12 & $-.18^{*}$ & 1 & - & - & - & - \\
\hline Openness (O) & .11 & -.05 & .12 & -.02 & $.15^{*}$ & 1 & - & - & - \\
\hline $\begin{array}{l}\text { Willingness to Communicate } \\
\text { - Public Speaking (WTC-PS) }\end{array}$ & $.41^{* *}$ & $-.61^{* *}$ & .05 & $.20^{* *}$ & $-.36^{* *}$ & .11 & 1 & - & - \\
\hline $\begin{array}{l}\text { Communication Competence } \\
\text { - Public Speaking (SPCC-P) }\end{array}$ & $.40^{* *}$ & $-.53^{* *}$ & .02 & $.18^{*}$ & $-.44^{* *}$ & .14 & $.84^{* *}$ & 1 & - \\
\hline Public speaking anxiety (PSA) & $-.16^{*}$ & $.35^{* *}$ & .07 & -.01 & $.51^{* *}$ & -.01 & $-.33^{* *}$ & $-.43^{* *}$ & 1 \\
\hline
\end{tabular}

Table 2

Hierarchical multiple regression equations using the enter method

\begin{tabular}{|c|c|c|c|c|c|c|c|}
\hline \multirow[t]{2}{*}{ DV } & \multirow[t]{2}{*}{ IV } & \multicolumn{3}{|c|}{ Model 1} & \multicolumn{3}{|c|}{ Model 2} \\
\hline & & $\beta$ & $t$ & $p$ & $\beta$ & $t$ & $p$ \\
\hline \multirow[t]{6}{*}{ WTC-PS } & Introversion & -.54 & -8.69 & .001 & -.49 & -7.97 & .001 \\
\hline & Agreeableness & -.07 & -1.17 & .246 & -.03 & -0.47 & .643 \\
\hline & Conscientiousness & .14 & 2.31 & .022 & .09 & 1.34 & .165 \\
\hline & Neuroticism & -.13 & -2.01 & .037 & -.11 & -1.73 & .085 \\
\hline & Openness & .11 & 1.91 & .058 & .08 & 1.40 & .163 \\
\hline & Desire for control & & & & .21 & 3.42 & .001 \\
\hline \multirow[t]{6}{*}{ SPCC-PS } & Introversion & -.39 & -6.21 & .001 & -.35 & 5.50 & .001 \\
\hline & Agreeableness & -.12 & -1.96 & .051 & -.08 & -1.30 & .195 \\
\hline & Conscientiousness & .14 & 2.13 & .034 & .08 & 1.27 & .206 \\
\hline & Neuroticism & -.30 & -4.66 & .001 & -.28 & -4.35 & .001 \\
\hline & Openness & .18 & 3.05 & .003 & .15 & 2.58 & .011 \\
\hline & Desire for control & & & & .20 & 3.21 & .002 \\
\hline \multirow[t]{6}{*}{ PSA } & Introversion & .16 & 2.43 & .016 & .16 & 2.37 & .019 \\
\hline & Agreeableness & .14 & 2.05 & .042 & .14 & 2.01 & .046 \\
\hline & Conscientiousness & .04 & 0.58 & .565 & .04 & 0.54 & .589 \\
\hline & Neuroticism & .48 & 7.08 & .001 & .48 & 7.02 & .001 \\
\hline & Openness & -.08 & -1.29 & .197 & -.08 & -1.28 & .201 \\
\hline & Desire for control & & & & .004 & 0.05 & .957 \\
\hline
\end{tabular}

Note. DV - dependent variable, IV - independent variable 
The next HMR analysis used SPCC-PS as the criterion. Four of the Big Five were significant predictors. Introversion, conscientiousness, neuroticism and openness all show significant contributions to prediction for Model $1(R=.62, F(5,190)=23.93, p<.001)$, accounting for $38.6 \%$ of the variance. For Model 2, with DC added, the results show that introversion, neuroticism, openness and DC all were significant predictors of SPCC-PS $(R=.65, F(6,189)=22.64$, $p<.001)$. Model 2 explains an additional $3.2 \%$ of the variance compared to Model 1.

The final HMR examines the prediction model for PSA. The results show that introversion, agreeableness and neuroticism contribute significantly to the regression model in Model $1(R=.56, F(5,189)=17.39$, $p<.001)$. The Big Five predictors account for $31.5 \%$ of the variance in PSA. In Model 2, there was no additional variance explained when DC was added to the model $(R=.56, F(6,188)=14.41, p<.001)$ because DC has a non-significant regression coefficient.

\section{DISCUSSION}

It is apparent from the zero-order correlations that in public speaking situations, people with higher DC tend to be more willing to communicate and perceive themselves to be both more competent and, to a weaker extent, less anxious. Similar patterns with respect to WTC and SPCC were identified in MacIntyre and Donovan's (2004) research whose results refer to communication patterns combining public speaking, meetings, small group and dyadic contexts. However, the present results diverge from MacIntyre and Donovan's (2004) in considering the correlation of DC with anxiety and contrast with Iba's (2007) suggestion that anxiety and desire for control might be positively correlated. For public speaking contexts, the present results are consistent with Wrench et al. (2008), who found a significant correlation between DC and anxiety, though the correlations of DC with PSA is notably weaker than for DC with WTC-PS and SPCC-PS.

The pattern of results supports the idea that desire for control can be exercised via public speaking. The individual differences suggest that the more DC a person shows, the more willing they are to give a public speech and the more competent they perceive themselves to be. PSA is weakly correlated with DC and may be operating in a background position. The correlations suggest that PSA could be considered only a mild restraining force. At some times, PSA offers a possible reason to avoid public speaking but at other times, it might simply be a reaction to be managed by the speaker within the search for opportunities to exert control.

The role of DC does not appear to be redundant with other personality traits reflected in the Big Five.
The results identified similar patterns of correlation involving introversion and neuroticism. As expected, those with higher levels of introversion and neuroticism (emotional volatility) tend to be less willing to communicate, perceive themselves as less competent, and experience higher anxiety during public speaking opportunities. Scores on scales of introversion and neuroticism tend to be intercorrelated with each other (Howarth, 1986; Verduyn \& Brans, 2012), and they show similar correlational patterns with communication traits such as CA, WTC, and SPCC (MacIntyre et al., 1999; McCroskey et al., 2001). McCroskey and colleagues (2001) found significant correlations between extraversion and CA as well as between neuroticism and CA. The present results support the argument that PSA exhibits similar patterns of correlation as the more broadly applicable scale of CA. As McCroskey and Richmond (1991) stated, "regardless of the operationalization of the construct, research overwhelmingly indicates that people who experience high levels of fear or anxiety about speaking tend to avoid and withdraw from communication" (p. 142).

For the second research question, the results indicate that there is benefit to examine the predictive validity of DC in relation to communication behaviors, in conjunction with the prediction afforded by the Big Five personality traits. In the first HMR, among the Big Five, introversion, conscientiousness, and neuroticism were all identified as significant predictors of WTC-PS. People who tend to be more passive or nervous show lower WTC-PS, and those who tend to be better organized or thoughtful show higher WTC-PS. Within the context of a regression equation, each of these traits makes a unique contribution to predicting WTC-PS; that is, the combination of traits offers better prediction than the traits offer individually. The addition of DC to the list of predictors, however, dramatically changed the equation, dropping conscientiousness and neuroticism to non-significant levels. Interpreting regression coefficients can be problematic because of the ways in which variance is allocated among predictors. Therefore, we cautiously offer the interpretation that DC specifically plays a facilitating role in generating WTC in public, a more direct role than traits such as conscientiousness and neuroticism. If public speaking especially taps into the motive for controlling the thoughts and actions of other people, it appears to be a context in which individual differences in DC can be actualized. At the very least, the results indicate that DC adds significant prediction of WTC-PS that is not redundant with prediction offered by the Big Five.

Within the second HMR, four of the Big Five traits (introversion, conscientiousness, neuroticism and openness) were significant predictors of SPCC-PS. However, the addition of DC rendered conscientiousness a non-significant predictor. This might suggest 
that the control-oriented component might be most responsible for the link between SPCC-PS and conscientiousness. If a person high in DC is more willing to speak in public, opportunities for practice and skill development likely would encourage the increasing perception of competence in that context. Other traits, specifically introversion, neuroticism, and openness, also appear to play a role in the process. It is important not to conflate perceptions of competence with actual competence. Indeed, as McCroskey and Richmond (1991) argue, perceived competence may be more relevant to communicating than actual competence, especially at the moments in which a person decides which communication opportunities to pursue.

The final HMR, predicting PSA, did not provide evidence of a contribution from DC. The equation results show that introversion, agreeableness, and neuroticism all contribute significantly to predicting PSA. In the presence of the results for WTC and SPCC, it might be suggested that PSA is an emotional reaction to be managed and controlled as one pursues opportunities to exert control. This would help to explain the low, but significant correlation between PSA and DC obtained here, and the inconsistent pattern of correlation between DC and indices of anxiety found in the research literature.

This study has several limitations that must be noted in interpreting its results. One limitation is the use of university students as research participants. Another limitation comes from the reliability coefficients, some of which are at the low end of the acceptable range and likely attenuate the obtained correlations. In addition, the measure of the Big Five is brief: future research with a more complex measure of the traits might generate interesting patterns of relationships among the specific facet scores comprising the five broad traits. Finally, we have examined only three communication traits; many more traits might be relevant to the issue of exerting control through public speaking, such as trait argumentativeness (see Avtgis \& Rancer, 1997).

\section{CONCLUSIONS}

This study provides evidence that the desire for control (DC), in conjunction with other personality traits, is related to feeling able and willing to communicate in public speaking contexts, with public speaking anxiety being relevant to a lesser extent. On balance, the results of this study are consistent with previous research showing that both broad and narrow traits are associated with communication. Each individual communicator possesses interacting personality traits that are especially relevant to certain situations. Speaking in a public context appears especially attractive to persons with a desire for control.

\section{RefERENCES}

Allport, G. W., \& Odbert, H. S. (1936). Trait-names: a psycho-lexical study. Psychological Monographs, 47, 1-171. https://doi.org/10.1037/h0093360

Amoura, C., Berjot, S., Gillet, N., \& Altinas, E. (2014). Desire for control, perception of control: Their impact on motivation and psychological adjustment. Motivation and Emotion, 38, 232-335. https://doi. org/10.1007/s11031-013-9379-9

Avtgis, T. Ä., \& Rancer, A. S. (1997). Argumentativeness and verbal aggressiveness as a function of locus of control. Communication Research Reports, 14, 441450. https://doi.org/10.1080/08824099709388687

Bochner, A. P., Kaminski, E. P., \& Fitzpatrick, M. A. (1977). The conceptual domain of interpersonal communication behavior: a factor-analytic study. Human Communication Research, 3, 291-302. https://doi.org/10.1111/j.1468-2958.1977.tb00532.x

Burger, J. M. (1990). Desire for control and interpersonal interaction style. Journal of Research in Personality, 24, 32-44. https://doi.org/10.1016/0092-6566(90)90004-P

Burger, J. M. (1992). Desire for control: Personality, social, and clinical perspectives. New York: Plenum. https://doi.org/10.1007/978-1-4757-9984-2

Burger, J. M. \& Cooper, H. M. (1979). The desirability of control. Motivation and Emotion, 3, 381-393. Retrieved from http://www.scu.edu/cas/psychology/ faculty/upload/Burger-Cooper-ME-1979.pdf

Burger, J. M., \& Solano, C. H. (1994). Changes in desire for control over time: Gender differences in a ten-year longitudinal study. Sex Roles, 31, 465472. https://doi.org/10.1007/BF01544201

Burgoon, J. K., \& Hale, J. L. (1984). The fundamental topoi of relational communication. Communication Monographs, 51, 193-214. https://doi.org/10.1080/ 03637758409390195

Costa, P. T., \& McCrae, R. R. (1985). The NEO personality inventory manual. Odessa, FL: Psychological Assessment Resources.

Funder, D. C. (2010). The personality puzzle ( $5^{\text {th }}$ ed.). London: W. W. Norton and Co.

Gebhardt, W. A., \& Brosschot, J. F. (2002). Desirability of control: Psychometric properties and relationships with locus of control, personality, coping, mental and somatic complaints in three Dutch samples. European Journal of Personality, 16, 423438. https://doi.org/10.1002/per.463

Goldberg, L. R. (1992). The development of markers for the Big-Five factor structure. Psychological Assessment, 4, 26-42. https://doi.org/10.1037/10403590.4.1.26

Hensley, W. E., \& Batty, P. (1974). The measurement of communication anxiety among students in public speaking courses. Indiana Speech Journal, 7-10.

Howarth, E. (1986). Introversion and neuroticism: a persistent relationship. Psychological Reports, 58, 389-390. https://doi.org/10.2466/pr0.1986.58.2.389 
Huang, L. N. (1999). Family communication patterns and personality characteristics. Communication Quarterly, 47, 230-243. https://doi.org/10.1080/ 01463379909370136

Iba, D. L. (2007). Hardiness and public speaking anxiety: Problems and practices. Doctoral dissertation. Denton: University of North Texas.

John, O. P., \& Srivastava, S. (1999). The Big-Five trait taxonomy: History, measurement, and theoretical perspectives. In L. A. Pervin \& O. P. John (Eds.), Handbook of personality: Theory and research (pp. 102-138). New York: Guilford Press.

Kello, J. (2012). Can introverts take the lead? Industrial Safety \& Hygiene News, 46, 28-30.

Kuofie, M., Stephens-Craig, D., \& Dool, R. (2015). An overview perception of introverted leaders. International Journal of Global Business, 8, 93-103.

Maclntyre, P. D. (1994). Variables underlying willingness to communicate: a causal analysis. Communication Research Reports, 11, 135-142. https://doi. org/10.1080/08824099409359951

Maclntyre, P. D., Babin, P. A., \& Clément, R. (1999). Willingness to communicate: Antecedents and consequences. Communication Quarterly, 47, 215229. https://doi.org/10.1080/01463379909370135

Maclntyre, P. D., \& Donovan, L. A. (2004). Desire for control and communication-related personality variables. Psychological Reports, 94, 581-582. https://doi.org/10.2466/PR0.94.2.581-582

McCrae, R. R., \& John, O. P. (1992). An introduction to the five-factor model and its applications. Journal of Personality, 60, 175-215. https://doi.org/10.1111/ j.1467-6494.1992.tb00970.x

McCroskey, J. C. (1970). Measures of communication-bound anxiety. Speech Monographs, 37, 269277. https://doi.org/10.1080/03637757009375677

McCroskey, J. C. (1982). An introduction to rhetorical communication (4 $4^{\text {th }}$ ed.). Englewood Cliffs, NJ: Prentice-Hall.

McCroskey, J. C., Heisel, A., \& Richmond, V. P. (2001). Eysenck's big three and communication traits: Three correlational studies. Communication Monographs, 68, 360-366. https://doi.org/10.1080/ 03637750128068

McCroskey, J. C., \& McCroskey, L. L. (2013). Self-perceived communication competence scale (SPCC). Measurement Instrument Database for the Social Science. Retrieved from www.midss.ie

McCroskey, J. C., \& Richmond, V. P. (1987). Willingness to communicate. In J. C. McCroskey \& J. A. Daly (Eds.), Personality and interpersonal communication (pp. 119-131). Newbury Park, CA: Sage.

McCroskey, J. C., \& Richmond, V. P. (1991). Willingness to communicate: a cognitive view. In M. Booth-Butterfield (Ed.), Communication, Cognition, and Anxiety (pp. 19-37). Newbury Park, CA: Sage.

Millar, F. E., \& Rogers, E. (1976). A relational approach to interpersonal communication. In G. R. Miller
(Ed.), Explorations in interpersonal communication (pp. 87-104). Beverly Hills, CA: Sage.

Missioura, O. (2014). Commitment, communication, and leadership determine the leader: a qualitative analysis businessperson characteristics practiced by SME and family business director. China-USA Business Review, 13, 115-130. https://doi.org/ 10.17265/1537-1514/2014.02.004

Richmond, V. P., \& McCroskey, J. (1985). Communication: Apprehension, avoidance, and effectiveness. Scottsdale, AZ: Gorsuch Scarisbrick Publishers.

Rubin, R. B., Perse, E. M., \& Barbato, C. A. (1988). Conceptualization and measurement of interpersonal communication motives. Human Communication Research, 14, 602-628. https://doi. org/10.1111/j.1468-2958.1988.tb00169.x

Sloan, J., \& Slane, S. (1990). Personality correlates of anxiety about public speaking. Psychological Reports, 67, 515-522. https://doi.org/10.2466/ pr0.1990.67.2.515

Smith, R. A., Wallston, B. S., Wallston, K. A., Forsberg, P. R., \& King, J. E. (1984). Measuring desire for control of health care processes. Journal of Personality and Social Psychology, 47, 415-426. https:// doi.org/10.1037/0022-3514.47.2.415

Smith, R. A., Woodward, N. J., Wallston, B. S., Wallston, K. A., Rye, P., \& Zylstra, M. (1988). Health care implications of desire and expectancy for control in elderly adults. Journal of Gerontology: Psychological Sciences, 43, 1-7. https://doi. org/10.1093/geronj/43.1.P1

Verduyn, P., \& Brans, K. (2012). The relationship between extraversion, neuroticism and aspects of trait affect. Personality and Individual Differences, 52, 664-669. https://doi.org/10.1016/j.paid.2011.12.017

Woodward, N. J., \& Wallston, B. S. (1987). Age and health care benefits: Self efficacy as a mediator of low desire for control. Psychology and Aging, 2, 3-8. https://doi.org/10.1037/0882-7974.2.1.3

Wrench, J. S., Brogan, S. M., McCroskey, J. C., \& Jowi, D. (2008). Social communication apprehension: The intersection of communication apprehension and social phobia. Human Communication, 11, 401-422.

Yu, H., Li, H., \& Gou, X. (2011). The personality-based variables and their correlations underlying willingness to communicate. Asian Social Science, 7 , 253-257.

Zaccardi, M., Howard, C., \& Schnusenberg, O. (2012). Student preparation and personality traits in the job market. Academy of Educational Leadership Journal, 16, 35-53. 